\title{
Kritik Sosial, Pers dan Politik Indonesia
}

\author{
Oleh Akhmad Zaini Abar
}

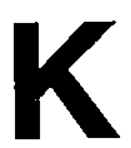

ritik sosial adalah salah satu bentuk komunikasi dalam masyarakat yang bertujuan atau berfungsi sebagai kontrol terhadap jalannya sebuah sistem sosial atau proses bermasyarakat." Dalam konteks inilah kritik sosial merupakan salah satu variabel penting dalam memelihara sistem sosial. Berbagai tindakan sosial ataupun individual yang menyimpang dari orde sosial maupun orde nilai-moral dalam masyarakat dapat dicegah dengan memfungsikan kritik sosial. Dengan kata lain, kritik sosial dalam hal ini berfungsi sebagai wahana untuk konservasi dan reproduksi sebuah sistem sosial atau masyarakat."2)

Cara berpikir yang demikian sering dipakai oleh kaum fungsionalis dalam menempatkan kritik sosial dalam proses politik. ${ }^{3)}$ Kritik sosial menurut mereka harus bersumber dan merupakan bagian dari sistem itu sendiri. Kritik sosial di luar sistem dianggap sesuatu yang tabu dan tidak dapat diterima, bahkan dianggap sebagai tindakan subversif, sebab dianggap berakibat menggoncangkan sistem. Atas dasar itulah, dalam perspektif demikian, kritik sosial harus dilakukan berdasarkan normanorma atau aturan-aturan main dalam sistem tersebut.

Dalam praktik politik di negeri ini, terutama di masa Orde Baru, pendekatan yang demikian boleh dibilang yang paling banyak dianut oleh kalangan elit politik yang berkuasa di negeri ini. Elit politik sering kali melontarkan ucapan klise demikian: "Mengemukan kritik dibolehkan, tapi harus sesuai dengan aturan-aturan atau normanorma yang berlaku". Begitu pula ada ucapan demikian: "Mengemukakan kritik dibolehkan asal konstruktif". Artinya, mengkritik boleh asal tidak merusak bangunan sistem yang sudah status quo.

1)Baca artikel Akhmad Zaini Abar, "Kritik Sosial, Negara dan Demokrasi", Republika, 8 Maret 1994.

2) Pengertian lain tentang kritik sosial misalnya dapat dibaca tulisan Astrid S. Susanto, "Makna dan Fungsi Kritik Sosial dalam Masyarakat dan Negara", Prisma, No. 10, Oktober 1977.

3) Pendekatan fungsionalis dalam IImu Sosial dan Politik biasanya merujuk kepada pemikiran R.K Merton dalam buku Social Structure, Free Press III, Glencoe, 1957. Sementara dalam IImu Komunikasi dan Teori Komunikasi Massa biasanya merujuk pada pemikiran Carles R. Wright, "Functional Analysis and Mass Communications", Public Opinion Quarterly, 24, 1960.

Untuk memahami secara singkat tentang berbagai pendekatan atau perspektif dalam IImu Komunikasi khususnya, lihat Stephen W. Littlejohn Theories of Human Communi cations, Wadsworth Publishing Company, Belmont, California, 1996. 
Kritik sosial juga dapat berarti sebuah inovasi sosial.4) Dalam arti bahwa kritik sosial menjadi sarana komunikasi gagasan-gagasan baru —sembari menilai gagasan-gagasan lama - untuk suatu perubahan sosial. Kritik sosial dalam kerangka yang demikian berfungsi untuk membongkar berbagai sikap konservatif, status quo dan vested interest dalam masyarakat untuk perubahan sosial.

Kritik sosial dalam pengertian yang terakhir ini sering muncul ketika masyarakat atau sejumlah orang atau kelompok sosial dalam masyarakat menginginkan suasana baru, suasana yang lebih baik dan lebih maju, atau secara politis, suasana yang lebih demokratis dañ terbuka.

Perspektif kritik sosial yang demikian lebih banyak dianut oleh kaum kritis dan strukturalis. Mereka melihat bahwa kritik sosial adalah wahana komunikatif untuk suatu tujuan perubahan sosial.5)

Dalam praktik politik di negeri ini, perspektif demikian, dianggap sebagai pandangan di luar sistem. Pandangan demikian dianggap sebagai liberalis dan tidak sesuai dengan budaya timur, khusus budaya di negeri ini (dalam kerangka budaya politik elit yang berkuasa) yang melihat kritik sebagai bagian dari suatu sistem.

\section{Kritik Sosial dan Pers Nasional}

Kritik sosial dapat disampaikan melalui berbagai wahana, mulai dari cara yang paling tradisonal, seperti pepe (berjemur diri), ungkapan-ungkapan sindiran melalui komunikasi antar personal dari komunikasi sosial, melalui berbagai pertunjukan sosial dan kesenian dalam komunikasi publik, seni sastra dan melalui media massa. Wahana yang terakhir inilah, yakni media massa, hingga kini dianggap paling efektif, populer, rasional serta institusional. Adapún jenis media massa yang paling efektif dan artikulatif dalam menyampaikan kritik sosial adalah pers (media cetak). ${ }^{6}$

Bagi pers, menyampaikan kritik sosial adalah salah satu cara menjalankan salah satu fungsi normatifnya, yakni sebagai satu alat kontrol sosial." Menyampaikan kritik sosial bagi pers juga bermakna sebagai cara bagaimana pers menyalurkan aspirasi sosial, aspirasi masyarakat. Begitu pula, menyampaikan kritik sosial bagi pers adalah salah cara bagaimana memposisikan pers sebagai wahana katarsis sosial, sarana pelepasan kegelisahan, keprihatinan dan bahkan kemarahan masyarakat. ${ }^{8}$ )

Seluruh makna kritik sosial bagi diri pers tersebut nampaknya cenderung lebih banyak berhadapan dengan aspek power, kekuasaan negara atau pemerintah. Kekuasaan negara di sini didefinisikan sebagai sosok yang punya kecederungan distorsif, eksesif, represif, koruptif, kolusif dan lain-lain sehingga perlu dikontrol, diawasi, dikritik. Kekuasaan yang cenderung otoriter, tidak demokratis, tidak mempertimbangkan

4)Akhmad Zaini Abar, "Kritik Sosial, Negara dan Demokrasi", op.cit.

${ }^{5)}$ Lihat Thomas B. Farrell and James A. Aune, "Critical Theory and Communication: A Selective Review", Quarterly Journal of Speech 65 (1979).

6) Kritik sosial tentu saja juga dapat diselenggarakan melalui media lain, seper ti radio siaran, televisi siaran ataupun film sekalipun daya politisnya rendah. Baca Akhmad Zaini Abar, "Kritik Sosial di Televisi Swasta", tabloid Citra, No.224N/28 November 4 Desember 1994.

7)Bahasan lengkap tetang pers dan fungsi-fungsinya, lihat Ashadi Siregar, Pers, Laporan Penelitian, Jurusan Ilmu Komunikasi Fisipol UGM, Yogyakarta, 1992.

8)Tentang ini baca Akhmad Zaini Abar, "Pers dan Katharsis Sosial", Republika, 21 Juli 1994. 
aspirasi masyarakat, karena itu, perlu memperhatikan pers sebagai suara masyarakat.

Agar kemarahan dan kebencian masyarakat terhadap tindakan kesewenang-wenangan kekuasaan tidak eksplosif dan meledak menjadi kerusuhan, maka pers perlu menyalurkannya dengan cara menjadikan dirinya sebagai wahana katarsis sosial.

Posisi pers yang cenderung berhadapan dengan kekuasaan ini menurut Denis McQuail, memang merupakan fitrah pers. Kata McQuail bahwa sejak awal perkembangannya pers (ia menyebut surat kabar) sudah menjadi lawan nyata atau musuh penguasa mapan. Citra pers yang dominan dalam sejarah, kata McQuail, selalu dikaitkan dengan pemberian hukuman bagi para pengusaha percetakan, penyunting dan wartawan yang berjuang untuk memperoleh kebebasan penerbitan, kemerdekaan pers, penegakkan hak asasi manusia dan demokrasi. ${ }^{9)}$

Di dalam praktik politik di berbagai negeri, termasuk Indonesia, memang tidak semua pers fitrahnya selalu merupakan bagian dari kontrol atas perilaku kekuasaan. ${ }^{10)}$ Ada cukup banyak pers yang justru diciptakan atau merupakan bagian dari kekuasaan itu sendiri. Di Indonesia misalnya, ada sejumlah pers yang kelahirannya, pengelolaannya, oritentasi redaksional, sumber daya manusianya dan kapitalnya seluruhnya berasal dari negara. ${ }^{11)}$ Misalnya saja harian Berita Yudha sebelum pergantian kepemilikannya tahun 1996, juga harian Angkatan Bersenjata dan Suara Karya.

Perlu dicatat pula di sini bahwa ada argumen lain yang mengatakan bahwa penyaluran kritik sosial melalui pers juga punya fungsi bisnis, di mana hanya pers yang kritis dan aspiratiflah yang akan dibaca dan tentunya dibeli orang. ${ }^{12)}$ Pers yang banyak menyalurkan kritik sosial, aspirasi masyarakat dan menghindarikan diri menjadi bagian dari kekuasaan akan lebih banyak diminati pembaca atau masyarakat. Pers yang diminati pembaca berarti pers yang punya khalayak yang luas. Khalayak yang luas inilah yang membuat para pengusaha, produsen atau biro iklan untuk memasang iklan di pers tersebut. Pada sisi inilah pers yang. kritis menjadi komersial, dalam arti berhasil mengembangkan dan meningkatkan kapitalnya.

\section{Kritik Sosial Pers dan Kekuasaan Negara}

Penyaluran atau artikulasi kritik sosial melalui pers dalam format politik di mana kekuasaan sangat eksesif, represif dan dominatif amat problematik. ${ }^{13)}$ Dalam konteks

9Denis McQuail, Teori Komunikasi Massa, Suatu Pengantar, Penerbit Erlangga, Jakarta, 1989.

10) Tentang sejarah pers kaum pribumi dalam perpolitikan kolonial, lihat Ahmat B. Adam, "The Vernaculer Press and the Emergence of Modern Indonesian Conscious ness, 1855-1913)", doctoral dissertation, Universiti Kebangsaan Malaysia

11)Tentang ini lihat Akhmad Zaini Abar, Kisah Pers Indonesia, 1966-1974, LKiS, Yogyakarta, 1995.

12) Baca artikel Akhmad Zaini Abar, "Hubungan antara Media, Iklan dan Demokrasi", Bisnis Indonesia, 2 Nopember 1996. Juga wawancara Goenawan Mohamad, "Pembaca Tak Suka Pers yang Jadi Alat Penguasa" dalam Media Indonesia Minggu, 16 Pebruari 1997.

13)Dalam format politik yang demokratis (apalagi demokrasi liberal) kritik sosial melalui pers nyaris tanpa ada masalah. Sebab, kekuasaan yang demokratis membutuhkan kritik sosial baik untuk legitimasi politik formal maupun untuk lancarnya mekanisme sistem politik. Atas dasar itulah kritik sosial melalui pers sangat menarik diperbincangkan dalam format politik yang represif dan dominatif. 
ini, pers bukan saja harus berhati-hati dan harus pandai-pandai menyusun siasatnya agar tidak mati konyol, juga sering terpaksa harus berkompromi dan terkadang hanyut dalam dinamika dan perilaku kekuasaan. Keadaan pers nasional di masa Orde Baru dapat dilihat dalam posisi problematis yang demikian.

Format politik di masa Orde Baru di mana negara yang kini cenderung semakin personalised ${ }^{14)}$ sangat kuat dan dominatif, manakala berhadapan dengan unsur-unsur masyarakat, kritik sosial melalui pers semakin sulit dikemukakan. ${ }^{15)}$ Sekalipun dapat dikemukakan oleh pers, dalam situasi politik tertentu, kritik sosial tidak punya makna sebagai inovasi sosial seperti yang dikemukakan di atas. Kritik sosial tidak berhasil memberi inspirasi atau mendorong perubahan sosial.

Hasil penelitian penulis tentang makna kritik sosial (kritik masyarakat) terhadap tiga distorsi perilaku kekuasaan negara pada periode awal Orde Baru menunjukan kecenderungan di atas. ${ }^{16)}$ Pertama, kritik sosial terhadap fenomena korupsi yang menggejala sejak kekuasaan Orde Baru mulai bercokol di negeri ini. ${ }^{17)}$ Kritik sosial ini dikemukakan oleh pers nasional sejak tahun 1967 hingga menjelang peristiwa Malari (Malapetaka Januri 1974). Kritik terhadap korupsi ketika dikemukakan pers dengan sangat keras, tajam dan bahkan tanpa tedeng aling-aling. ${ }^{18)}$ Lihat saja contoh kutipan tajuk tiga harian yang terbit ketika itu.

\section{Bensin, Korupsi dan Pemilu}

"Pada mulanya demonstrasi-demonstrasi mahasiswa/pelajar digerakkan oleh karena memprotes kenaikkan harga bensin dan minyak tanah.
14)R. William Liddle, "Suharto's Indonesia: Personal Rule and Political Institusions ", $\mathrm{Pa}$ cific Affairs, Spring, 1985.

${ }^{15)}$ Format politik Orde Baru ini dapat dibaca dari beberapa kepustakaan berikut ini, Arief Budiman, "The Emergence of the Bureaucratic Capitalist State in 'Indonesian dalam Lim Tek Ghee, ed., Reflection on Development in Southeast Asia Institute of Southeast Asian Studies, 1988; Arief Budiman (ed) 1990, State and Civil Society in Indonesia Center of Southeast Asian Studies, Monash University, 1990; Farchan Bulkin, "Nasib Publik dalam Sebuah Republik" Prisma, no. 8, LP3ES, Jakarta, 1985; Dwight Y. King, 1982 "Indonesia's New Order as Bureacratic Polity, a Neopatrimonialism - Regime or Bureaucratic Authoritarian Regime: What Difference Does It Make?", in.Benedict R. O. G. Anderson and Audrey Kahin, ed., Interpreting Indonesian Politics: Thirteen Contributions to The Debat, Interm Reports Series, Cornell University, 1982; Mohtar Mas'oed, Ekonomi dan Struktur Politik Orde Baru 1966-1971 LP3ES, Jakarta, 1989. N.G. Schulte Nordholt, State-Citizen Relations in Suharto's Indonesia: Kawula-Gusti, CASP 16, Rotterdam, 1987; dan Richard Robison, "Toward a Class Analysis of Indonesia Military Bureaucracy State", Indonesia, No. 25, 1978.

16)Lihat Akhmad Zaini Abar, "Kebebasan Pers, Kekecewaan Masyarakat dan Keperka saan Negara", Prisma, No. 4/1994. Bahasan yang lebih mendalam, lihat Akhmad Zaini Abar, Kisah Pers Indonesia ... op.cit.

${ }^{17}$ Seperti diberitakan harian Sinar Harapan (29 Mei 1970) dengan mengutip komentar Newsweek apabila rezim Orde Lama (rezim Soekarno) dahulu baru memulai korup sinya setelah 3 tahun berkuasa, maka pemerintah Orde Baru telah korup mulai dari hari pertama berkuasa.

18)Pers nasional yang kritis terhadap korupsi ketika itu antara lain harian Indonesia Raya, Nusantara, Marian Kami, Pedoman, Duta Masyakarat, Sinar Harapan, Kompas, mingguan Mahasiswa Indonesia (edisi Jawa Barat) dan lain-lain. 
Pada suatu ketika mereka bertanya mengapa harga bensin dan minyak tanah dinaikkan? Untuk menambah penghasilan pemerintah dibutuhkan itu? Bukankah itu berarti memberatkan bagi penghidupan rakyat kecil? Mengapa tidak diambil dari orang-orang kaya atau PN Pertamina? Mengapa tidak diberantas korupsi kalangan super atasan? Tidakkah diketahui, bahwa Presiden dikelilingi oleh koruptor-koruptor dan bajingan-bajingan? Demikian pertanyaan mahasiswa atau pelajar. Jadi pada akhirnya issue yang pokok tetap adalah soal korupsi dan bukan sóal kenaikan harga minyak bumi. Tetapi soal korupsi ini tidak dapat ditanggulangi oleh pimpinan nasional, artinya tidak sedemikian rupa sehingga memenuhi keinginan generasi muda. Maka soal korupsi ini tetap tinggal hangat.

Lalu timbul segi. Kenaikan harga minyak itu antara lain perlu untuk turut membiayai pemilu di tahun 1971 yang akan memakan biaya Rp 15 milyar, demikian kata pemerintah. Berhadapan dengan segi ini mahasiswa atau pelajar bercabang dua pendiriannya. Ada yang berpendirian bahwa pemilu mutlak perlu, jadi biaya itu harus disediakan, bagaima-napun juga. Ada pula yang berpendirian bahwa soal pemilu berdasarkan UU Pemilu yang telah diterima oleh DPR-GR tidaklah menyangkut diri dan kepentingannya.

Maka dari sini kita lihat hubungan satu sama lain antara masalah bensin, masalah korupsi, dan masalah pemilu. Dan dari semua itu bagi mahasiswa atau pelajar kiranya tetap yang terpenting ialah masalah korupsi. Mengapa korupsi tidak di- basmi? (Dikutip tidak lengkap dari harian Pedoman, 29 Januari 1970).

\section{Kontrol Pengeluaran Uang PELITA}

"Menjelang berakhirnya tahun anggaran pembangunan 1 April yang lalu, kita memperoleh kesan: berbagai departemen segera melaksanakan proyek-proyek mengejar agar anggaran tidak keburu hangus!

Pengalaman seperti itu tak boleh berulang lagi. Prof. Wijoyo, Ketua Bappenas menegaskan, yang pokok bukanlah cepatnya beaya dikeluarkan atau dihabiskan, yang penting baik-tidaknya sebuah proyek dilaksanakan.

Kabarnya, karena mau memburu cepatnya anggaran keluar, terjadilah permainan. Permainan itu di antaranya, main kwitansi palsu, main kontraktor palsu. Dalam keadaan itu anggaran memang dikeluarkan, tetapi proyek tidak terwujud semestinya.

Permainan-permainan semacam itu membuktikan lagi perlunya pengawasan.

Kita berharap, bidang pengawasan ini untuk seterusnya diperhatikan benar, bukan hanya panas-panas pada permulaan tahun belaka.

Kontrol adalah pekerjaan yang paling tidak enak. terutama karena adanya salah pengertian tentang fungsi kontrol dalam masyarakat kita.

Menurut kebiasaan kita, kontrol identik dengan curiga, tidak percaya. Karena ditanggapi demikian, maka umumnya kita tidak suka dikontrol, marah. Padahal kontrol merupakan bagian yang esensial dari seriap tertib administrasi, apalagi administrasi 
Topik: Kritik Sosial, Pers dan Politik Indonesia..., Akhmad Zaini Ábar

keuangan. (Dikutip tidak lengkap dari harian Kompas, 4 April 1970)

\section{Pura-pura Tak Mengerti, Jendral lbnu?}

"Kita tak dapat menahan senyum dan rasa hati sedikit geli membaca dalam beberapa koran ucapań Jenderal Ibnu Sutowo, Direktur Utama PN Pertamina, yang mengatakan, bahwa sorotan pers terhadapnya akhir-akhir ini adalah 'fitnah yang terbantah sendiri oleh fakta-fakta.'

Harian ini telah menyiarkan serańgkaian fakta-fakta tentang mismanagement, penyelewengan dan korupsi di dalam Pertamina. Laporan-laporan itu diperkuat dengan pembuktian-pembuktian, dokumendokumen. Sebagian terbesar dari fakta-fakta yang kami siarkan adalah hasil-hasil pemeriksaan dan laporan yang disusun oleh petugas-petugas resmi badan-badan pemerintahan sendiri. Apakah Ibnu Sutowo mengatakan pembesar-pembesar Pemerintah Republik indonesia sendiri telah melakukan 'fitnah' terhadap dirinya? Atau mungkin lbnu Sutowo tak begitu paham apa arti kata 'fitnah' dalam bahasa Indonesia ini?

Ibnu Sutowo tak pernah sąnggup membantah fakta-fakta yang telah kami kemukakan. Pernah Humasnya mencoba membantah, akan tetapi kemudian terus bungkem, karena tak sanggup menghadapi faktafakta yang kami ajukan.

Laporan team Pekuneg tentang manipulasi dengan ekspor minyak mentah ....., manipulasi dengan harga ....., cara-cara pemakaian keuangan oleh Direktur Utama tanpa suatu pengawasan ....., pemesanan kapal lewat broker Jepang, dan puluhan lagi contoh-contoh salah arus dan penyelewengan, besar dan kecil : apakah semua ini 'fitnah' ?" (Dikutip tidak lengkap dari harian Indonesia Raya, 22 April 1970)

Respon pemerintah atau penguasa yang menjadi sasaran kritik sosial ketika itu cenderung berbelit-belit dan penuh retorika. Di mana-mana pejabat omong tentang kehendak memberantas korupsi. Tetapi, bersamaan dengan itu korupsi jalan terus dan meluas dari birokrasi di tingkat yang paling tinggi sampai ke tingkat yang paling bawah.

Pemerintah memang menciptakan kebijakan penanggulangan korupsi dengan menciptakan UU anti korupsi (UU No.3/ 1971) bersama DPR. Tetapi di dalam praktik politik, tidak ada seorang pun koruptur kelas kakap yang diperkaraan atau diadili dengan UU anti korupsi ini. Sementara itu, korupsi jalan terus dan terkesan dilindungi.

Hingga kini fenomena korupsi terus menggejala, bahkan dengan kuantitas dan kualitas yaing lebih dahsyat dibandingkan di awal-awal ketika pers dengan radikal menyampaikan kritik sosial.

Cerita yang sama juga terjadi pada isyu proyek pembanguan Taman Mini Indonesia Indah. Kritik sosial melalui pers terhadap Proyek yang langsung dibidani oleh Ibu Tien Soeharto ini juga tidak berhasil menggentarkan kelangsungan proyek ini yang selesai di tahun 1974.

Kritik sosial terhadap arah' dan strategi pembangunan Orde Baru juga mengalami hal yang sama, yakni kebijakan ekonomi dan politik yang simbolistik dan retoris. Lihat tabel di bawah ini:

Berdasarkan kasus yang diilustrasikan di atas dapat dikatakan bahwa kritik sosial melalui pers tidak berhasil menjadi inovasi 
sosial yang menjadi dasar bagi penciptaan kebijakan yang sesuai dengan aspirasi masyarakat atau dasar bagi perubahan sosial sesuai dengan tuntutan dan harapan masyarakat, dalam hal ini penanggulangan wabah korupsi di tubuh birokrasi negara serta penindakan koruptor kelas kakap, penundaan atau pembatalan Proyek Pembangunan Taman Mini Indonesia Indah dan perubahan strategi pembangunan dari GNP

\section{SKEMA KRITIK SOSIAL MELALUI PERS DAN RESPON NEGARA TAHUN 1966-1974}

\begin{tabular}{|c|c|c|c|}
\hline Tema Kritik & $\begin{array}{l}\text { Reaksi } \\
\text { Positif } \\
\text { Negara }\end{array}$ & $\begin{array}{l}\text { Reaksi } \\
\text { Negatif } \\
\text { Negara }\end{array}$ & Hasil \\
\hline $\begin{array}{l}\text { 1. Berantas Korupsi } \\
(1967-1968) \text {. }\end{array}$ & $\begin{array}{l}\text { Pembentukan TPK dan } \\
\text { Task Force } \\
\end{array}$ & $\begin{array}{l}\text { Tuduhan Merongrong } \\
\text { Kewibawaan Negara }\end{array}$ & $\begin{array}{l}\text { Tidak sesuai dengan } \\
\text { Harapan Masyarakat/ } \\
\text { penangkapan Korupsi } \\
\text { Kelas Teri. }\end{array}$ \\
\hline $\begin{array}{l}\text { 2. Berantas Korupsi } \\
(1969-1970)\end{array}$ & $\begin{array}{l}\text { Pembentukan Komisi } 4 \\
\text { dan UU No. } 3 / 1971 \\
\text { tentang PTPK. }\end{array}$ & $\begin{array}{l}\text { Tuduhan Merongrong } \\
\text { Ke wibawa } \mathrm{n} / \mathrm{Ke}- \\
\text { kuasaan Negara }\end{array}$ & Tidak Ada Hasil Nyata \\
\hline $\begin{array}{l}\text { 3. Batalkan atau } \\
\text { Tunda proyek MII } \\
(1971-1972)\end{array}$ & $\begin{array}{l}\text { Memorandum Pansus } \\
\text { DPR }\end{array}$ & $\begin{array}{l}\text { Penangkapan, Pena- } \\
\text { hanan Mahasiswa dan } \\
\text { interogasi wartawan/ } \\
\text { redaktur. }\end{array}$ & $\begin{array}{l}\text { Gagal: Proyek MII } \\
\text { Jalan Terus }\end{array}$ \\
\hline
\end{tabular}

oriented menjadi people and human ori: ented.

Berdasarkan hal ini dapat dikatakan kritik sosial yang dikemukakan pers tidak lebih dari hanya memproduksi kata-kata yang tidak punya makna bagi perubahan sosial ke arah yang lebih diharapkan masyarakat. Kritik sosial melalui pers hanya berhasil menciptakan retorika pejabat yang kemudian tidak menemukan tindakan atau aksi-aksi politik yang nyata. Dengan kata lain, kritik sosial melalui pers hanya melahirkan involusi kata-kata yang luhur.

Lebih dari itu, karena kritik sosial yang ditampilkan pers secara transparan dan keras inilah, akhirnya sejumlah penerbitan pers yang kritis di awal tahun 1974, yang terkenal dengan Peristiwa Malari,dibreidel. ${ }^{19}$

\section{Catatan Penutup}

Setelah peristiwa Malari 1974, di.mana sejumlah pers kritis dibreidel, pers nasional mulai mengurangi intensitas dan radikalitas kritik sosial yang disampaikannya. Apalagi pembreidelan terus berlangsung setiap kritik sosial pers kembali intens dan radikal, seperti di tahun 1978 , di tahun 1983 , tahun 1986 , di tahun 1987 . 1990, dan 1994.20)

Dalam perkembangannya, pers tidak hanya menurunkan intensitas dan radikali-

19) Lihat Akhmad Zaini Abar Kisah Pers Indonesia ... op.cit.

20)Baca David T. Hill, The Press in New Order, PT Pustaka Sinar Harapan, 1995. 
tas kritik sosial yang ditampilkannya, pers nasional bahkan kemudian menjadi ketakutan dengan hal-hal yang berbau kritik sosial, terutama yang ditujukan kepada perilaku kekuasaan dan aktor-aktor sentral kekuasaan. Selain itu, sejumlah pers bahkan sangat akomodatif dengan kehendak dan kepentingan kekuasaan, di mana wajah-wajah dan bahasa-bahasa kekuasaan banyak diproduksi dan direproduksi oleh pers secara sadar maupun tidak sadar. ${ }^{21)}$

Sementara itu, negara (state), di pihak lain terus menciptakan berbagai mekanisme rugulatif, represif maupun kooptasi terhadap pers agar tidak lagi kritis terhadap dinamika dan perilaku kekuasaan negara. ${ }^{22}$ Mekanisme regulatif dapat berupa penciptaan berbagai ketentuan hukum yang tidak memberikan peluang bagi pers untuk bebas dan merdeka dalam menjalankan tựgäs dan fungsi normatifnya. Mekanisme represif yakni melakukan berbagai tindakan menekan pers secara langsung, misalnya dengan menghimbau, menelpon (baca: mengancam), memanggil para pemimpin redaksi, melakukan teror terhadap wartawan ataupun keluarganya' (bahkan ada yang melakukan tindakan pembunuhan: kasus mungkin masuk dalam kategori ini Udin wartawan Bernas) dan terakhir mencabut izin terbit pers.

Kondisi demikian melahirkan semacam kesadaran di kalangan pers bahwa kritik sosial adalah sebuah fungsi pers yang amat sulit diartikulasikan dan berisiko amat tinggi bila difungsikan dalam konteks perpolitikan Orde Baru. Karena itu, setiap kali mengartikulasikan fungsi kritik sosialnya pers - terutama pers yang masih punya political'will-melakukannya dengan ekstra hati-hati. Kritik sosial sering disublimasikan secara canggih ke dalam hamparan berita dan informasi pers yang cenderung meng"kultus"kan kekuasaan negara dan pemimpin sentralnya. Berbagai metode berbahasa dan metode penulisan berita dipakai pers untuk menghaluskan makna kritik sosialnya sehingga tidak membangunkan amarah kekuasaan tetapi justru membangunkan "hati nurani" kekuasaan untuk memperbaiki dan mengotrol prilakunya.

Akan tetapi, yang sering terjadi adalah bahwa kecanggihan berbahasa dan teknik jurnalistik dalam penulisan berita - yang membawa pesan kritik sosial ini- justru semakin menyulitkan khalayak pers di negeri ini untuk menangkap makna tersirat dari berita dan informasi pers. Khalayak pers sering dibuat bingung oleh sebuah pemberitaan yang sesungguhnya misinya diniatkan untuk mengartikulasikan fungsi kritik sosial pers.

Pers seakan-akan hendak menuntut pembacanya untuk lebih cerdas dan kreatif dalam menangkap pesan-pesan kritik sosial di antara baris-baris kata dan kalimat yang disusunnya, sembari mengharapkan agar kekuasaan dapat memakluminya.

Demikian gambaran dan argumen singkat bagaimana problematik kritik sosial melalui pers nasional di hadapan kekuasaan negara Orde Baru.

21) Lihat Akhmad Zaini Abar, "Posisi Pers sebagai Kekuatan Menengah", Kompas, 7 Pebruari 1993.

${ }^{22)}$ Akhmad Zaini Abar, "Informasi, Negara dan Pembangunan", makalah yang disampaikan pada Seminar Pembangunan Struktur Politik Orde Baru: Pembangunan Demokrasi dan Demokratisasi di Indonesia, diselenggarakan oleh Korp Mahasiswa IImu Pemerin tahan Fisipol UGM Yogyakarta, 23 Nopember 1996. Makalah ini diterbitkan harian Bernas, 4 Desember 1996 dengan sedikit revisi. 